\title{
ALERGIA ALIMENTAR E O CENÁRIO REGULATÓRIO NO BRASIL
}

Food allergy and regulatory scenario in Brazil

La alergia alimentar y el escenario regulatorio en Brasil

Miriã Benatti Berzuino', Rita de Cassia de Souza Fernandes², Marina de Almeida Lima², Andréa Carvalheiro Guerra Matias², Isabela Rosier Olimpio Pereira1*

${ }^{1}$ Curso de Farmácia, Universidade Presbiteriana Mackenzie

${ }^{2}$ Curso de Nutrição, Universidade Presbiteriana Mackenzie

*E-mail: isabela.pereira@mackenzie.br

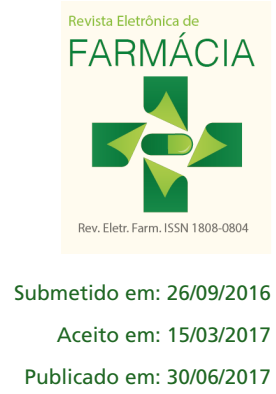

\section{RESUMO}

A alergia alimentar (AA), reação a determinadas proteínas, tem como principal tratamento a eliminação do alimento alergênico. Neste artigo, objetivou-se esclarecer causas, mecanismos fisiológicos e consequências da AA, além de comparar legislações de órgãos sanitários do Brasil e de outros países do mundo. Buscaram-se publicações em bases de dados, livros e documentos emitidos por órgãos regulatórios e sanitários, utilizando-se palavras chaves relacionadas. A AA é mais prevalente em crianças, sendo a proteína do leite de vaca o principal alérgeno, mas os sintomas tendem a desaparecer com a idade, enquanto que alergia ao amendoim, nozes e frutos do mar, podem durar a vida toda. A AA é um problema de saúde pública que vem crescendo nos países industrializados, sendo a anafilaxia uma manifestação clínica grave. A falta de declaração de substâncias alergênicas no rótulo de alimentos industrializados é a primeira causa de risco de segurança alimentar no mundo. O Brasil foi o primeiro país na América do Sul a regulamentar a obrigatoriedade da declaração de alergênicos nos rótulos. Outras regiões do mundo possuem legislação desde 2003. Desse modo, busca-se melhorar a qualidade de vida dos alérgicos e propiciar um consumo seguro de alimentos industrializados.

PALAVRAS-CHAVE: Hipersensibilidade alimentar. Alérgenos. Legislação sobre alimentos.

\section{ABSTRACT}

Food allergy (FA), a reaction to certain proteins, has as main treatment the elimination of allergenic food. The objective was to clarify causes, physiological mechanisms and consequences of FA, in addition to comparing legislation of health agencies in Brazil and other countries in the world. Publications were searched in databases, books and documents issued by regulatory and health agencies, using related keywords. FA is more prevalent in children, with cow's milk protein being the main allergen, but symptoms tend to disappear with age, while allergy to peanuts, nuts, and seafood can last a lifetime. FA is a public health problem that has been growing in industrialized countries, with anaphylaxis being a serious clinical manifestation. The lack of declaration of allergenic substances on the label of industrialized foods is the first cause of food safety risk in the world. Brazil was the first in South America to regulate the mandatory declaration of allergens on labels. Other regions of the world have had legislation since 2003. In this way, the aim is to improve the quality of life of allergy sufferers and to provide safe consumption of processed foods.

Keywords: Food Hypersensitivity. Allergens. Legislation. Food. 


\section{RESUMEN}

La alergia alimentar (AA), reacción a ciertas proteínas, tiene como tratamiento principal la eliminación del alimento alergénico. El objetivo de este artículo fue aclarar las causas, mecanismos fisiológicos y consecuencias de la AA, además de comparar las legislaciones de órganos sanitarios de Brasil y otros países del mundo. Se realizaron buscas en bases de datos, libros y documentos expedidos por las autoridades reguladoras y sanitarias, utilizando palabras clave relacionadas. La AA es más frecuente en niños, siendo la proteína de la leche de vaca el principal alérgeno, pero los síntomas tienden a desaparecer con la edad, mientras que la alergia al maní, nueces y frutos marinos puede durar toda la vida. La AA es un problema de salud pública que va en aumento en países industrializados, siendo la anafilaxia una manifestación clínica grave. La falta de declaración de sustancias alergénicas en las etiquetas de los alimentos industrializados es la primera causa del riesgo para la seguridad alimentaria en el mundo. Brasil fue el primer país en América del Sur a regular la declaración obligatoria de los alérgenos en las etiquetas. Otras regiones del mundo tienen legislación desde 2003. De este modo, se busca mejorar la calidad de vida de los alérgicos y proporcionar un consumo seguro de los alimentos industrializados.

Palabras clave: Hipersensibilidad alimentar. Alérgenos. Legislación sobre alimentos.

\section{INTRODUÇÃO}

A alimentação é um fator muito importante para a sobrevivência e manutenção do estado de saúde do indivíduo, pois além de suprir as necessidades nutricionais, envolve aspectos importantes nas relações psicossociais(1). A maioria das pessoas usufrui de grande diversidade de alimentação, porém, para algumas, certos alimentos podem causar reações adversas, como a alergia(2).

Alergia Alimentar $(\mathrm{A} A)$ é uma reação do sistema imunológico humano frente à exposição a uma proteína alimentar inócua que será reconhecida erroneamente pelo organismo como um imunógeno não próprio que deve ser eliminado. A fração do alimento responsável por desencadear a reação alérgica é denominada alérgeno(3).

A reação alérgica é caracterizada por duas fases: a fase de sensibilização e a fase da reação alérgica propriamente dita. Tudo se inicia com a exposição do organismo a uma proteína potencialmente alergênica, que irá formar anticorpos específicos por reconhecê-la erroneamente. Quando o corpo é exposto novamente ao alérgeno, ocorre a segunda fase da reação, que consiste na ativação dos mastócitos e na liberação de mediadores químicos, como por exemplo, histamina, prostaglandinas e citocinas que serão responsáveis pelos sintomas clínicos da alergia(4).

As reações alérgicas podem ser mediadas por imunoglobulina E ( $\operatorname{lgE}$ ) ou não. A produção de anticorpos IgE específicos são importantes nas reações de hipersensibilidade imediata do tipo 1. Porém, existem outras formas de hipersensibilidade alimentar, como por exemplo a enterocolite induzida por proteínas, na qual mecanismos imunes do tipo 4 não mediados por lgE parecem ser predominantes ${ }^{(5)}$.

Os sintomas clínicos da AA se manifestam normalmente no aparelho digestivo causando dores abdominais, diarreia e náuseas; no sistema respiratório causando tosse, asma e coriza; e na pele causando erupção, eczemas e coceiras. Segundo a Sociedade Brasileira de Pediatria e a Associação Brasileira de Alergia e Imunologia(6), casos mais graves podem levar a um choque anafilático e até à morte do indivíduo. A Sociedade ainda estima que, apesar de calcular-se nos Estados Unidos da América (EUA) que $5 \%$ das crianças e cerca de $4 \%$ dos adultos sofram de alergia alimentar, este número tende a aumentar cada vez mais, tornando a alergia alimentar um assunto de grande importância para as autoridades sanitárias de cada país ${ }^{(6)}$.

Mais de 170 alimentos são capazes de desencadear uma reação alérgica; porém, apenas um pequeno grupo é responsável por mais de $90 \%$ dos casos de AA. São esses os denominados "oito grandes" ou the big eight ${ }^{(3)}$. 
Infelizmente, o único tratamento para pessoas que possuem AA é evitar a ingestão desses alimentos, o que não é uma tarefa simples, visto que além do próprio consumidor ter grande responsabilidade na restrição do consumo de alergênicos, as indústrias alimentícias também devem se comprometer em relação à transmissão de informações corretas da presença de substâncias alérgenas na rotulagem dos produtos, assim como as autoridades sanitárias na criação de legislação pertinente e fiscalização para melhorar a qualidade de vida desses indivíduos ${ }^{(6)}$.

Um diagnóstico correto é imprescindível não só para direcionar o tratamento, mas também para evitar uma restrição alimentar desnecessária, que a longo prazo pode restringir determinados nutrientes e afetar o estado nutricional do indivíduo e seu desenvolvimento ${ }^{(2-7)}$.

Devido a toda a complexidade da AA e a dificuldade que os pacientes alérgicos e familiares enfrentam pela falta de informação em rótulos de alimentos industrializados, foi criada, em 2014, a Campanha Põe no Rótulo, a fim de mobilizar e conscientizar toda a população pela internet em relação à importância e a necessidade do direito à informação e a uma rotulagem correta, clara e com destaque dos ingredientes alergênicos, tendo grande repercussão após divulgação maciça pela mídia e apoio de famosos e pessoas públicas.

Por todos esses aspectos, a Agência Nacional de Vigilância Sanitária (ANVISA) publicou uma Consulta Pública n²29, de 05 de junho de 2014, que discorreu sobre a obrigatoriedade das indústrias alimentícias de declarar no rótulo a presença de alergênicos ${ }^{(8)}$; esta consulta foi essencial para a publicação da Resolução da Diretoria Colegiada (RDC) $n^{\circ} 26$, de 2 de julho de 2015, que dispõe sobre os requisitos para rotulagem obrigatória dos principais alimentos que causam $\mathrm{AA}^{(9)}$.

Em virtude dos fatos mencionados, o objetivo dessa revisão sistemática é esclarecer as causas, mecanismos fisiológicos e consequências da AA, além de estabelecer uma comparação das atitudes em termos de legislação do órgão sanitário do Brasil e de outros países do mundo. Ademais, essa revisão também está organizada em sessões que buscam elucidar a epidemiologia de AA, diferenciar a fisiopatologia de AA, doença celíaca e intolerância alimentar, bem como evidenciar os principais alimentos envolvidos na alergia e o seu tratamento.

\section{PROCEDIMENTOS METODOLÓGICOS}

Trata-se de um artigo de revisão em que realizou-se uma pesquisa bibliográfica em publicações de revistas nacionais e internacionais através do Portal CAPES e do Google Acadêmico por meio do uso das palavras-chave: hipersensibilidade alimentar, hipersensibilidade, alérgenos, legislação e suas respectivas traduções em inglês, além de big eight, escolhido pelos autores devido à temática do trabalho. O intervalo de publicação dos artigos utilizados foi de 1994 a 2015 . A busca também se estendeu a livros de imunologia e da área de nutrição, assim como documentos emitidos por órgãos regulatórios e sanitários de diversos países, como a ANVISA, Food and Drug Administration (FDA) e Food Standards Australia New Zeland (FSANZ).

\section{RESULTADOS E DISCUSSÃO}

Dados sobre alergia alimentar

As reações adversas aos alimentos são representadas por qualquer reação anormal do organismo frente à ingestão de alimentos. Podem ser classificadas em tóxicas e não tóxicas. As reações tóxicas dependem mais da substância ingerida, como toxinas bacterianas presentes em algum alimento contaminado, ou ainda de propriedades farmacológicas de determinadas substâncias presentes em alimentos, como a cafeína no café. As reações não tóxicas são aquelas que dependem da susceptibilidade de cada indivíduo e podem ser classificadas como: não imuno-mediadas ou imuno-mediadas, onde se encontra a AA. 
Alergia alimentar é o termo utilizado para descrever reações adversas a alimentos, dependentes de mecanismos imunológicos, mediada por anticorpos ou células, sendo que na maioria dos casos o anticorpo envolvido é a IgE. Portanto, a AA é caracterizada por ser uma resposta imune exacerbada a proteínas alimentares que são absorvidas pela mucosa intestinal(2).

A etiologia da AA ainda não é totalmente conhecida, mas sabe-se que a potência antigênica de alguns alimentos, histórico familiar e alterações intestinais parecem ter um papel muito importante na determinação da doença(10). Como exemplo, observa-se que a imaturidade da mucosa intestinal em crianças é um fator que vem sendo apontado como explicação para a maior incidência da AA em crianças e lactentes, pois a maior permeabilidade intestinal permite a absorção de proteínas ou frações protéicas intactas, estimulando a resposta imune ${ }^{(2)}$. O trato gastrointestinal maduro possui mecanismos para evitar a passagem de moléculas possivelmente alergênicas pela mucosa intestinal, como a acidez gástrica e a digestão enzimática, responsáveis por fragmentar as moléculas protéicas em peptídeos não antigênicos ${ }^{(3)}$.

Outro fator importante refere-se ao dado de que 50 a 70\% dos pacientes com AA possuem história familiar de alergia. Além disso, a probabilidade de o filho ser alérgico caso os pais possuam alergia é de $75 \%{ }^{(6)}$.

\section{PRINCIPAIS ALIMENTOS ALERGÊNICOS: THE BIG EIGHT}

Os alérgenos alimentares são representados por glicoproteínas hidrossolúveis com peso molecular entre 10 e 70 kDa, termoestáveis e resistentes à ação de ácidos e proteases, sendo capazes de desencadear resposta humoral e celular. Existem mais de 170 alimentos que podem levar ao aparecimento de reações alérgicas, porém, apenas pequena parte deles é responsável por mais $90 \%$ dos quadros de AA. São esses os The Big Eight ou ainda oito grandes, representados no Quadro 1, assim como os ingredientes relacionados encontrados nos rótulos de alimentos industrializados ${ }^{(11)}$.

Quadro 1 - Alimentos alergênicos e suas possíveis nomenclaturas

\begin{tabular}{|c|c|}
\hline $\begin{array}{c}\text { Alimento } \\
\text { Alergênico }\end{array}$ & Ingredientes Correspondentes \\
\hline Leite & Soro de Leite, whey protein, caseína, lactato, nata, caseinato de potássio, \\
entre outros.
\end{tabular}

Fonte: PROTESTE, PÕE NO RÓTULO, 2014(27)

A alergia ao amendoim é a causa mais comum de morte relacionada à $A A^{(12)}$, sendo que outros alimentos também são amplamente conhecidos por desenvolverem a sintomatologia observada, como semente de girassol, damasco, aipo, 
mostarda ou ainda aditivos alimentares como os sulfitos, que mesmo em baixas concentrações podem levar a uma reação de hipersensibilidade ${ }^{(3)}$

Outro fator importante são as reações cruzadas que podem ocorrer entre os alimentos devido à similaridade de uma determinada sequência de aminoácidos presente em um epítopo alergênico. As principais proteínas responsáveis por reatividade cruzada se encontram na Tabela 1.

TABELA 1 - Exemplos de alérgenos com similaridade de seqüências protéicas e consequente risco de reações cruzadas.

\begin{tabular}{lcc}
\hline Alérgico a: & Risco de reação a: & Risco em \% \\
\hline Amendoim & Ervilha, lentilha, feijão & $5 \%$ \\
Nozes & Castanha-do-pará, avelã & $37 \%$ \\
Salmão & Peixe-espada, linguado & $50 \%$ \\
Camarão & Caranguejo, lagosta & $75 \%$ \\
Trigo & Centeio, cevada & $20 \%$ \\
Leite de vaca & Carne (bovina) & $10 \%$ \\
& & \\
Pólen & Leite de cabra & $92 \%$ \\
Látex & Maçã, pêssego, melão & $55 \%$ \\
\hline
\end{tabular}

Fonte: SICHERER, 2001(33)

É válido ressaltar que existe ainda a contaminação cruzada dos alimentos, referente à presença não intencional de algum alérgeno que normalmente não estaria presente no produto final. Entre as potenciais fontes de contaminação cruzada em uma indústria alimentícia que podem afetar alimentos industrializados estão os equipamentos compartilhados, as partículas de ar, a limpeza, o transporte, o estoque e as próprias pessoas envolvidas na fabricação dos produtos ${ }^{(13)}$. Assim, um gerenciamento deve ocorrer a fim de evitar essa presença não intencional, o que envolve avaliação de risco na linha de produção, separação de utensílios, separação de matérias-primas alergênicas no estoque, entre outras ações.

\section{TIPOS DE ALERGIA ALIMENTAR E SINTOMATOLOGIA}

O processo de reação alérgica se inicia com a exposição do organismo frente a uma substância potencialmente alergênica em que uma série de reações irão ocorrer no organismo, como ativação dos linfócitos T helper 2 (Th2) e linfócitos B, produção da IgE específica, e ligação do anticorpo a receptores da porção Fc dos mastócitos ${ }^{(4)}$. Quando o organismo é novamente exposto ao alérgeno, ocorre a segunda fase da reação, que consiste na ativação dos mastócitos que contêm o anticorpo em sua superfície e na liberação de mediadores químicos como, por exemplo, histamina, prostaglandinas e citocinas que serão responsáveis pelos sintomas clínicos da alergia(4).

As reações de hipersensibilidade aos alimentos podem ser classificadas de acordo com o mecanismo imunológico envolvido, mediadas por IgE, não mediadas por lgE ou ainda mistas, ou seja, quando ocorrem concomitantemente ${ }^{(5)}$. 
A reação de hipersensibilidade mediada por IgE é denominada hipersensibilidade do Tipo I, caracterizada pela formação de anticorpos específicos da classe IgE após a exposição a uma proteína alimentar alergênica. Esses anticorpos formados irão se ligar na superfície de mastócitos e basófilos, o que resultará em sensibilização. De tal forma, ao ocorrer uma exposição subsequente os alérgenos, estes irão se ligar a lgE específica e liberar mediadores químicos como a histamina, prostaglandinas e leucotrienos, responsáveis pelo aparecimento dos sintomas que ocorrem minutos após a ingestão do alimento, que geralmente são agudos, podendo ser de ordem cutânea, gastrointestinal, respiratória e sistêmica, como erupção cutânea aguda ao redor dos lábios; rubor; edema de face; urticária; dificuldade respiratória; vômitos e anafilaxia(5,6).

Vale referir que a AA é uma das causas mais comuns de anafilaxia, que apesar de rara pode ser fatal(2). A anafilaxia é caracterizada como uma reação sistêmica aguda, grave, que atinge diversos órgãos e sistemas simultaneamente e é determinada pela atividade de mediadores químicos como a histamina, prostaglandinas e citocinas liberados por mastócitos e basófilos ativados. O quadro clínico da anafilaxia compreende em mais de $90 \%$ dos casos manifestações cutâneas, como urticária e rubor; comprometimento variável do aparelho respiratório, como dispneia e sibilância (55-60\%) e angioedema de vias aéreas superiores (mais de 25\%); aparelho cardiovascular, com tonturas, hipotensão, visão turva (30-35\%); sistema nervoso, causando cefaleias (5-8\%) e convulsões (1-2); e trato gastrintestinal, com náuseas, vômitos, diarreia e dor (25-30\%)(14).

Outro tipo de reação, a não mediada por lgE, é denominada de hipersensibilidade tardia ou hipersensibilidade do tipo IV, e é mediada por linfócitos TCD4+ padrão, linfócitos T helper 1 (Th1) e macrófagos. Sendo assim, ocorrerá infiltração destas células no local onde o antígeno está presente. Os macrófagos são células fagocitárias, apresentadoras de antígenos aos linfócitos T e podem exercer quimiotaxia. Eles produzem interleucina 2 (IL-2) que auxilia na resposta dos linfócitos TCD4+ padrão Th1, caracterizando a imunidade celular ${ }^{(15)}$.

As reações mediadas por células não são tão imediatas, representam a minoria das reações imunológicas aos alimentos, e as manifestações clínicas mais comuns são proctite e enterocolite, e estes podem demorar de horas até dias para se manifestarem ${ }^{(2)}$.

Enquanto o grupo classificado como reação mista é caracterizado pelas manifestações decorrentes de mecanismos mediados por IgE, com participação de linfócitos T e de citocinas pró-inflamatórias ${ }^{(5,6)}$.

Vários fatores contribuem para o predomínio de uma resposta celular (Th1) ou humoral (Th2), como propriedades e dose do antígeno, local da exposição e manutenção da resposta imune ${ }^{(15)}$.

\section{EPIDEMIOLOGIA DA ALERGIA ALIMENTAR}

A AA é um problema de saúde pública que vem crescendo nos países industrializados. É estimado que 1/4 da população mundial irá enfrentar uma reação adversa a alimento durante a vida. Por isso, tal tema merece atenção por parte da população e da mídia, visto que uma manifestação clínica bem grave relacionada à AA é a anafilaxia(16).

Calcula-se que nos EUA, $5 \%$ das crianças e cerca de $4 \%$ dos adultos sofram de AA. As alergias causadas pelo leite de vaca, ovo, trigo e soja tendem a desaparecer ainda na infância; em relação ao amendoim, nozes e frutos do mar, podem demorar mais para desaparecer, ou ainda, durar a vida toda ${ }^{(6)}$. Em crianças de até dois anos de idade, a proteína do leite de vaca é o alérgeno mais frequentemente observado, afetando de 2 a 3\% das crianças no primeiro ano de vida. Cerca de $50 \%$ destas crianças desenvolvem alergia a outros alimentos, e em torno de $80 \%$ para aeroalérgenos, como por exemplo, o pólen ${ }^{(2)}$.

Crianças que possuem AA são até 4 vezes mais propensas a desenvolver outra condição relacionada, como a asma, em relação a crianças que não possuem AA. Adicionado a isso, de 4 a $8 \%$ das crianças com asma possuem $A A^{(17)}$. Outro dado importante refere que aproximadamente $35 \%$ das crianças com dermatite atópica apresentam AA mediada por IgE.

De acordo com um estudo realizado em 2013 pelo Centers for Disease Control and Prevention nos EUA, a AA aumentou cerca de $50 \%$ em crianças no período entre 1997 e $2011^{(18)}$. Mesmo diante do notável aumento dos casos no Brasil, até o momento não há dados precisos sobre a prevalência dessa hipersensibilidade alimentar ${ }^{(19)}$. 
Mudanças no estilo de vida e nos hábitos alimentares da sociedade de hoje são fatores que contribuem para o aumento da prevalência da AA. Além disso, apontam-se fatores como: exposição à alérgenos alimentares durante gravidez e lactação, dieta ocidental com ingestão de elevada proporção de Ômega 6 em relação a Ômega 3, exposição ao tabaco e utilização de medicamento antiácido ${ }^{(20)}$.

\section{DIAGNÓSTICO DE ALERGIA ALIMENTAR}

O diagnóstico de uma reação de hipersensibilidade alimentar é complexo, visto que a história clínica tem papel fundamental, assim como a correta descrição dos sintomas apresentados por parte do paciente como frequência e intensidade e a possível relação com algum alimento previamente ingerido ${ }^{(21)}$.

A história clínica do paciente é associada aos dados de exames físicos que são complementados por testes alérgicos realizados in vivo ou in vitro. Os testes realizados in vivo são o teste cutâneo de hipersensibilidade imediata, denominados também de Prick test, e os testes de provocação oral, considerado padrão ouro para o diagnóstico da AA. Já os testes in vitro são aqueles que irão verificar a presença de lgE sérica específica ${ }^{(10)}$.

O teste de provocação oral consiste na oferta de alimentos ou placebos em doses crescentes e intervalos regulares, sendo esse procedimento realizado sob supervisão médica para monitoramento de possíveis reações clínicas. Pode ser classificado em aberto, em que o paciente e o médico têm conhecimento da substância ingerida, se é alimento ou placebo; simples-cego, no qual apenas o médico sabe o que está sendo administrado; ou ainda duplo-cego, no qual nenhuma das partes sabe o que está sendo administrado ao paciente. O teste duplo-cego é o considerado padrão-ouro; porém, devido aos altos custos, tempo dispensando para a realização do procedimento e a probabilidade de reações graves, sua prática clínica é limitada (21).

Assim, o teste de hipersensibilidade cutâneo é o teste mais comumente utilizado devido à sua segurança, simplicidade, baixo custo e rapidez. Ele se baseia em medir IgE específica ligada às células da pele. $\mathrm{O}$ exame é realizado no antebraço do paciente, onde o examinador faz pequenas marcas com caneta na pele do paciente identificando qual alérgenos está sendo testado, depositando pequenas gotas de extrato padronizado do alimento ao lado das marcações, assim como o controle positivo, que utiliza a histamina e o controle negativo, que utiliza solução salina. Após a introdução epicutânea dos alérgenos, aguarda-se um período de 15 minutos para realizar a leitura do exame. Os resultados positivos são aqueles que apresentam formação de pápula com pelo menos $3 \mathrm{~mm}$ de diâmetro médio superior ao controle negativo. Na falta de extrato padronizado se utiliza o alimento in natura ${ }^{(10)}$.

Já os testes in vitro são utilizados para verificar a presença de IgE específica no sangue, assim como a presença de basófilos ativados após a sensibilização. Essa dosagem é capaz de detectar 95\% dos casos de AA mediadas por lgE. Dentre as diversas metodologias utilizadas no diagnostico in vitro, destacam-se o método de ELISA (enzyme-linked immunosorbent assay), o sistema ImmunoCap®, o teste de ativação de basófilos e os microarrays $46^{(9)}$.

\section{TRATAMENTO DA ALERGIA ALIMENTAR}

O tratamento para AA preconizado hoje se refere à exclusão absoluta do alimento responsável pelos sintomas da dieta do alérgico. Por isso, a dieta de exclusão deve ser respaldada por um diagnóstico correto e preciso, visto que a retirada de um alimento pode colocar o paciente, em especial crianças em fase de amamentação, em risco nutricional sendo de grande necessidade e importância a monitoração e educação continuada dos pais e cuidadores para um tratamento de sucesso. A dieta de exclusão tem como objetivo evitar o reaparecimento de sintomas, proporcionando assim uma melhor qualidade de vida para o paciente. Porém, por outro lado esta é uma tarefa árdua, visto que muitos alérgenos estão presentes em alimentos amplamente utilizados na culinária, como leite, ovos e trigo ${ }^{(20,22,23)}$. 
Além de interromper a ingestão do alimento, o tratamento deve ocorrer para o alívio dos sintomas que foram desencadeados, sendo que, na maioria dos casos, os pacientes são liberados com prescrição de anti-histamínico oral por no mínimo sete dias, e em alguns ainda se faz necessário o uso de corticosteroides orais ${ }^{(6)}$.

Em casos de sintomas mais graves que possam estar evoluindo para edema de glote ou choque anafilático, pode ocorrer até a necessidade de hospitalização do paciente. É importante reconhecer as manifestações clínicas relacionadas à anafilaxia, visto que a ingestão indevida de alimentos por pacientes alérgicos é a causa mais comum de levar à anafilaxia nos EUA, principalmente em crianças $^{(24)}$.

A anafilaxia é uma das mais dramáticas e temidas condição clínica de emergência médica, devido a sua gravidade e imprevisibilidade. Além disso, determina um grande impacto na vida daqueles que são afetados pelo problema, assim como dos familiares $^{(14)}$. Para a reversão dos sintomas da anafilaxia, deve ser administrado adrenalina aquosa de concentração $1 / 1000$ na dose de 0,2 a 0,5 ml (em crianças de 0,01 mg/kg a 0,3 mg/kg) por via intramuscular na face anterolateral da coxa de cinco em cinco minutos até o desaparecimento dos sintomas ${ }^{(24)}$. A intervenção subsequente depende da resposta terapêutica à adrenalina e da gravidade da reação anafilática(14).

Devido à grande chance que o paciente tem de desenvolver uma reação grave, têm se buscado novos planos terapêuticos para o controle da AA. Alguns estudos estão se mostrando promissores, como imunoterapia específica, vacinas de DNA de alérgenos, ervas medicinais chinesas, imunoterapia não específica, aleitamento materno e probióticos, porém ainda necessitam de mais estudo(21).

\section{ALERGIA ALIMENTAR, INTOLERÂNCIA ALIMENTAR E DOENÇA CELÍACA}

As reações adversas ao alimento podem ser divididas em imuno-mediadas (AA e doença celíaca) e não imuno-mediadas (intolerância alimentar), sendo, portanto, válido esclarecer que existem diferenças entre elas. A AA está relacionada a uma resposta imunológica do organismo frente ao alimento, enquanto que a doença celíaca é uma doença autoimune que se caracteriza por uma reação imunológica contra o próprio intestino delgado perante a ingestão de glúten que está presente em alguns cereais. Já a intolerância alimentar se caracteriza por uma deficiência metabólica do organismo em relação às enzimas digestivas ${ }^{(3,7)}$.

A intolerância à lactose, frequentemente confundida com alergia alimentar ao leite, é uma reação adversa que não envolve o sistema imunológico e ocorre devido à deficiência da enzima lactase, sendo classificada como uma intolerância alimentar.

Um diagnóstico correto é de suma importância, visto que indivíduos com AA toleram quantidades muito baixas de leite, podendo desenvolver reações graves como choque anafilático; enquanto que os indivíduos com intolerância à lactose toleram quantidades maiores de leite podendo apresentar sintomas abdominais como dor e distensão abdominal, flatulência, diarreia, náusea, vômitos ou constipação devido à má digestão da lactose.

Diferentemente das anteriores, a doença celíaca é uma doença autoimune inflamatória do intestino delgado que se manifesta em indivíduos geneticamente suscetíveis devido à ingestão de glúten, fração protéica encontrada em alimentos como trigo, centeio, cevada e aveia. Os indivíduos com doença celíaca apresentam sintomas como diarreia, perda de peso devido à má absorção intestinal, deficiência de ferro, entre outros ${ }^{(7)}$. Além disso, acredita-se que indivíduos com doença celíaca podem tolerar pequenas quantidades de glúten na alimentação como 10 mg/dia sem manifestações clínicas, diferentemente de indivíduos com alergia alimentar ao trigo, em que quantidades bem inferiores de glúten podem ser suficientes para desencadear reações $\operatorname{adversas}^{(9)}$. 


\section{REGULAMENTAÇÃO DA ROTULAGEM DE PRODUTOS ALERGÊNICOS}

Devido à complexidade da AA, à dificuldade encontrada pelos pacientes e familiares em garantir uma alimentação livre de alergênicos e à falta de informações claras e corretas em rótulos de alimentos industrializados, a obrigatoriedade de regulamentação para uma declaração correta e efetiva vem sendo cada vez mais exigida tanto no Brasil como em outros países, que tem como objetivo direcionar, padronizar e controlar as informações referentes à rotulagem de um produto industrializado em relação à presença intencional e/ou não intencional de um alérgeno, de modo a facilitar a compreensão dos consumidores e evitar o risco de estes apresentarem uma reação de hipersensibilidade ao alimento que está sendo consumido.

Estudos apontam a grande dificuldade na leitura da lista de ingredientes no rótulo dos produtos, devido ao excesso de informação, termos não conhecidos ou ainda ilegibilidade. Além disso, muitas vezes as informações fornecidas não são confiáveis, ou são imprecisas, corroborando assim para a necessidade da padronização da informação, de forma simples, clara e fácil de ser localizada(25). Observa-se, na Figura 1, que a falta de declaração de substâncias alergênicas no rótulo é a primeira causa de risco de segurança alimentar em todo o mundo.

FIGURA 1 - Relação dos Riscos de Segurança Alimentar

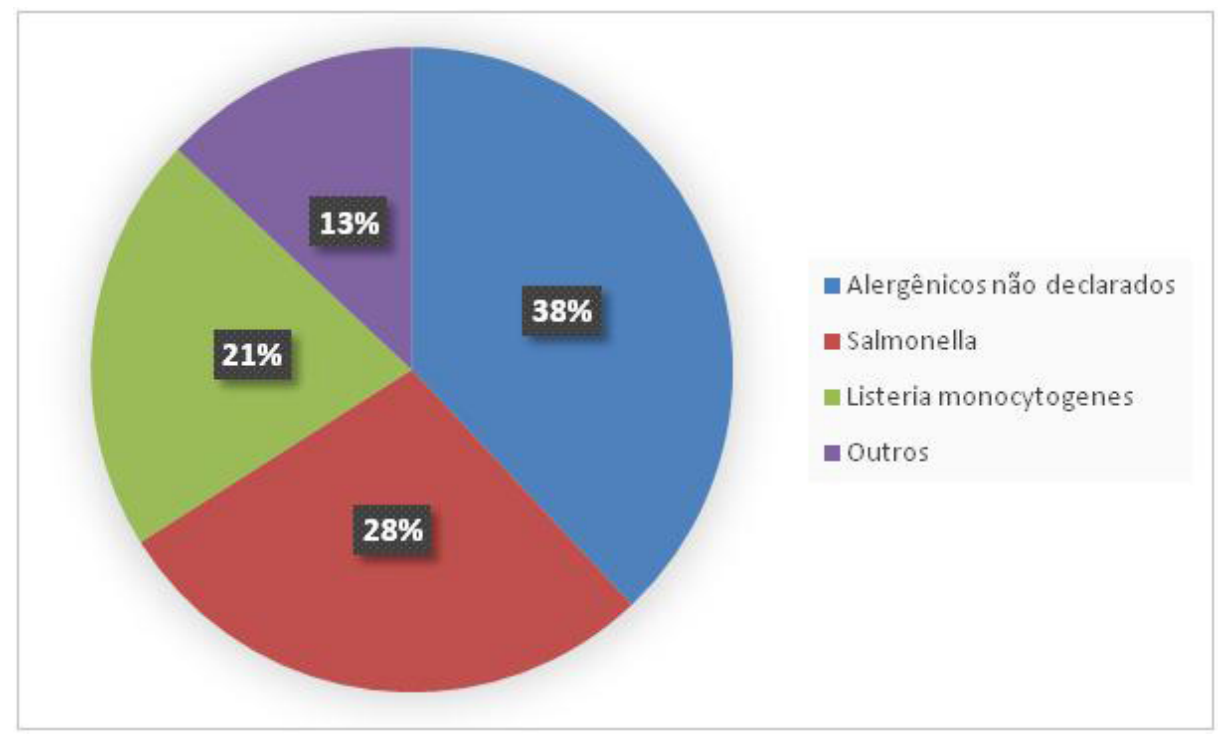

Fonte: U.S. FOOD AND DRUG ADMINISTRATION, 2014(34)

\section{NO BRASIL}

Visando a relação existente entre o direito à saúde e o direito à vida, assim como a inter-relação entre o direito à saúde e o direito à alimentação adequada, deve-se garantir a disponibilidade de alimentos livres de alérgenos para a parcela da população que possuir AA. Assim, é de responsabilidade do Estado a proteção destes direitos relacionados à saúde e a alimentação 
adequada para estas pessoas que necessitam de maior atenção e informação sobre a presença de alérgenos nos rótulos de produtos industrializados ${ }^{(19)}$.

Segundo os artigos $6^{\circ}, 8^{\circ}, 12^{\circ}$ e $31^{\circ}$ da Lei n 8.078/1990, são direitos básicos do consumidor ${ }^{(26)}$ :

III - A informação adequada e clara sobre os diferentes produtos e serviços, com especificação correta de quantidade, características, composição, qualidade, tributos incidentes e preço, bem como sobre os riscos que apresentem; [...]

Art. $8^{\circ}$ Os produtos e serviços colocados no mercado de consumo não acarretarão riscos à saúde ou segurança dos consumidores, exceto os considerados normais e previsíveis em decorrência de sua natureza e fruição, obrigando-se os fornecedores, em qualquer hipótese, a dar as informações necessárias e adequadas a seu respeito.

Parágrafo único. Em se tratando de produto industrial, ao fabricante cabe prestar as informações a que se refere este artigo, através de impressos apropriados que devam acompanhar o produto. [...]

Art. 12. O fabricante, o produtor, o construtor, nacional ou estrangeiro, e o importador respondem, independentemente da existência de culpa, pela reparação dos danos causados aos consumidores por defeitos decorrentes de projeto, fabricação, construção, montagem, fórmulas, manipulação, apresentação ou acondicionamento de seus produtos, bem como por informações insuficientes ou inadequadas sobre sua utilização e riscos. [...]

Art. 31. A oferta e apresentação de produtos ou serviços devem assegurar informações corretas, claras, precisas, ostensivas e em língua portuguesa sobre suas características, qualidades, quantidade, composição, preço, garantia, prazos de validade e origem, entre outros dados, bem como sobre os riscos que apresentam à saúde e segurança dos consumidores.

Nesse cenário de demandas da sociedade, de ações públicas, divulgação maciça feita pela mídia e por pessoas famosas e influentes, além da Campanha Põe no Rótulo(27), a ANVISA regulamentou, por meio de uma publicação no Diário Oficial da União, a RDC $n^{\circ} 26$, de 02 de julho de 2015, que dispõe sobre os requisitos para rotulagem obrigatória dos principais alimentos que causam $\mathrm{AA}^{(25)}$. Além disso, a regulamentação orienta as indústrias quanto à necessidade de um Programa de Controle de Alergênicos e instrui como deve ser feita a rotulagem correta da informação sobre os alérgenos presentes na composição do alimento $^{(25)}$

Assim sendo, de acordo com o artigo $6^{\circ}$ da $\operatorname{RDC} n^{\circ} 26$, de 02 de julho de 2015, "os alimentos, ingredientes, aditivos alimentares e coadjuvantes de tecnologia que contenham ou sejam derivados dos alimentos listados no Anexo devem trazer a declaração "Alérgicos: Contém (nomes comuns dos alimentos que causam alergias alimentares)", "Alérgicos: Contém derivados de (nomes comuns dos alimentos que causam alergias alimentares)" ou "Alérgicos: Contém (nomes comuns dos alimentos que causam alergias alimentares) e derivados", conforme o caso". 
Em adição à RDC n²6, o artigo $7^{\circ}$ acrescenta que "nos casos em que não for possível garantir a ausência de contaminação cruzada dos alimentos, ingredientes, aditivos alimentares ou coadjuvantes de tecnologia por alérgenos alimentares, deve constar no rótulo a declaração "Alérgicos: Pode conter (nomes comuns dos alimentos que causam alergias alimentares)".

Estas advertências devem estar agrupadas logo abaixo da lista de ingredientes e de forma legível; além disso, devem estar inseridas em uma caixa que faça contraste com o fundo da embalagem e nunca se deve utilizar tamanho de letra inferior ao utilizado para listar os ingredientes, sendo altura mínima de $2 \mathrm{~mm}$ e, no caso das embalagens com área de painel principal igual ou inferior a $100 \mathrm{~cm}^{2}$, de $1 \mathrm{~mm}{ }^{(25)}$. A RDC ainda traz um prazo de 12 meses para adequação de todos os rótulos, contados a partir da data de publicação(25).

A lista dos alimentos que são de rotulagem obrigatória inclui trigo, centeio, cevada, aveia e suas estirpes hibridizadas; crustáceos; ovos; peixes; amendoim; soja; leites de todas as espécies de animais mamíferos; amêndoas (Prunus dulcis, sin.: Prunus amygdalus, Amygdalus communis L.); avelãs (Corylus spp.); castanha-de-caju (Anacardium occidentale); castanhado-brasil ou castanha-do-pará (Bertholletia excelsa); macadâmias (Macadamia spp.); nozes (Juglans spp.); pecãs (Carya spp.); pistaches (Pistacia spp.); pinoli (Pinus spp.); castanhas (Castanea spp.); e látex natural(25).

Embora desde o ano de 2011 o Brasil esteja discutindo a harmonização das regras de rotulagem em relação aos alimentos com alergênicos na Comissão de Alimentos do Subgrupo Técnico 3 (SGT-3) do Mercado Comum do Sul (MERCOSUL), a publicação da RDC n 26 de 02 de julho de 2015 não está harmonizada com o bloco econômico, sendo então uma decisão unilateral que é indiretamente benéfica aos consumidores. Ainda, devido à falta de dados nacionais para a elaboração da lista dos principais alimentos causadores da AA, foram utilizadas referências técnico-científicas e regulatórias internacionais ${ }^{(25)}$.

\section{NOS ESTADOS UNIDOS DA AMÉRICA}

Os EUA preocupam-se com informação nutricional em seus rótulos alimentares desde o início do século XX; de tal forma, a disponibilização nos rótulos alimentares quanto aos ingredientes contidos nos alimentos, mesmo que não direcionados especificamente ao público alérgico, facilitou um maior entendimento, tomando maior amplitude após regulamentação do FDA em 1938(28). Apesar disso e devido ao aumento do número de casos de AA, mesmo com tentativas prévias de levar uma maior informação aos alérgicos alimentares na década de 90 por meio da Nutrition Labeling and Education Act, da publicação "Food Allergies: Rare But Risky" pelo FDA bem como seu incentivo à declaração voluntária de ingredientes alergênicos foi apenas em 02 de Agosto de 2004, após aprovação pelo Food Allergen Labeling and Consumer Protection Act (FALCPA), que se tornou obrigatória a declaração dos oito alérgenos mais comuns nos rótulos de forma simples e em uma lista separada dos ingredientes, sendo eles leite; ovos; peixe; crustáceos; frutos secos; amendoins; trigo; e soja ${ }^{(29)}$.

\section{NA UNIÃO EUROPEIA}

Na União Europeia, a questão de padronização da rotulagem de alergênicos já ganhou importância desde 10 de novembro de 2003, quando a Diretiva 2003/89/CE foi aprovada pelo Parlamento Europeu e pelo Conselho Europeu, determinando a declaração de alergênicos no rótulo de produtos alimentícios, incluindo as bebidas(30).

Com o intuito de proteger a saúde dos consumidores e garantir o direito à informação, a Diretiva 2003/89/CE contempla uma lista de ingredientes potencialmente alergênicos, dos quais se faz necessária a rotulagem, sendo eles cereais que contém glúten, como trigo, centeio, cevada, aveia; crustáceos; ovos; peixes; amendoins; leite; soja; frutos secos como amêndoas, avelã, nozes, castanhas, pistache; aipos; mostarda; sementes de gergelim, bem como os produtos feitos a base desses ingredientes. Além disso, dióxido de enxofre e sulfitos em concentrações superiores a $10 \mathrm{mg} / \mathrm{kg}$ também precisam ser declarados nos rótulos dos alimentos. 


\section{NA AUSTRÁLIA}

Na Austrália a questão de rotulagem de alergênicos teve início em 2002 pelo Standard 1.2.3, atualmente revogado pelo Standard 5.1.1, constituindo-se como o responsável por trazer a obrigatoriedade de declarar os alergênicos nas embalagens de produtos alimentícios, sendo os principais componentes e seus derivados obrigatoriamente rotulados nos cereais contendo glúten; crustáceos; ovos; peixes; leites; amendoim; gergelim; soja e frutos secos, além de sulfitos em concentração maior ou igual a $10 \mathrm{mg} / \mathrm{kg}^{(31)}$

A Food Standards Australia New Zealand (FSANZ), agência regulatória da Austrália, realizou um levantamento referente aos recalls realizados nos últimos 10 anos e evidenciou que $32 \%$ do total é devido à falta de rotulagem de alergênico na embalagem ${ }^{(32)}$

\section{CONSIDERAÇÕES FINAIS}

A AA é uma reação adversa do organismo frente a um alimento através de manifestações imunológicas, sendo os responsáveis por $90 \%$ dos casos os chamados the big eight. Devido aos diversos sintomas observados, dentre eles a reação anafilática, um diagnóstico correto é fundamental para que se exclua o alimento alergênico da dieta. De tal forma, devido a dificuldades advindas da falta de informações claras e corretas em rótulos de alimentos industrializados, diversos países regulamentaram a rotulagem de alergênicos para facilitar a compreensão dos consumidores e evitar o risco de este apresentar uma reação de hipersensibilidade ao alimento.

Notou-se que, apesar de existirem particularidades típicas de cada regulamentação que exigem a declaração de alergênicos específicos, como a declaração de látex natural no Brasil e do gergelim na Austrália, os oito alimentos que mais causam AA são de obrigação comum em todos, confirmando a prevalência do envolvimento destes nos casos de AA.

Tal comparação também evidenciou um atraso da legislação brasileira em 11 anos quanto à rotulagem obrigatória da presença de alérgenos em relação a países como EUA e Austrália, visto que somente após a cobertura e a atenção maciça realizada pela mídia e pela população, a RDC $n^{\circ} 26$ veio a ser publicada. No entanto, observou-se que a decisão proposta pela ANVISA a fim de proteger a saúde dos consumidores foi pioneira em relação aos países membros do MERCOSUL.

Espera-se, com essa nova legislação, que os consumidores que possuem AA e suas famílias possam ter uma qualidade de vida melhor, e que, para isso, as indústrias cumpram o compromisso e sejam ágeis para atender ao prazo de um ano dado pela ANVISA para regularização das embalagens. Para tal, é essencial uma efetiva fiscalização por parte do governo e que membros da sociedade se mobilizem na denúncia e se conscientizem acerca da necessidade do direito à informação e à rotulagem com destaque aos ingredientes potencialmente alergênicos.

\section{REFERÊNCIAS}

1. BRASIL. Ministério da Saúde. Secretaria de Atenção à Saúde. Guia Alimentar para a população brasileira. Brasília, 2014.

2. TEIXEIRA ARN. Alergias Alimentares na infância. Porto: Universidade do Porto; 2010.

3. REYAM, SILVESTRE AA. Comer sem risco 2: As doenças transmitidas por alimentos. 2st ed. São Paulo: Livraria Varela; 2009.

4. NUNES M, MOREIRA A, MORAIS-ALMEIDA M, MOREIRA P, BARROS R. Avaliação do estado nutricional em crianças com alergia alimentar. Revista Portuguesa de Cirurgia; 2011; 26.

5. ABBAS AK, LICHTMAN AH, PILLAI S. Imunologia celular e molecular. Rio de Janeiro: Elsevier Brasil; 2015. 
6. SOCIEDADE BRASILEIRA DE PEDIATRIA E ASSOCIAÇÃO BRASILEIRA DE ALERGIA E IMUNOLOGIA. Consenso brasileiro sobre alergia alimentar. Rev. Bras. Alerg. Imunopatol. 2008;31(2).

7. FERREIRA CT, SEIDMAN E. FOOD ALLERGY: a practical update from the gastroenterological view point. Jornal de pediatria; 2007;83(1):7-20

8. BRASIL. Ministério da Saúde. Agência Nacional de Vigilância Sanitária. Consulta Pública n. 29, de 05 de junho de 2014. Declaração obrigatória na rotulagem de alimentos embalados das fontes reconhecidas por causarem alergias ou intolerâncias alimentares em pessoas sensíveis. Diário Oficial da União 2014. [acesso em 06 jun 2015]. Disponível em: http://portal. anvisa.gov.br

9. BRASIL. Ministério da Saúde. Agência Nacional de Vigilância Sanitária. Resolução da Diretoria Colegiada n.26, de 02 de julho de 2015. Requisitos para Rotulagem Obrigatória dos Principais Alimentos que Causam Alergias Alimentares. Diário Oficial da União 2015.

10. RAMOS REM, LYRA NRS, DE OLIVEIRA CM. Alergia alimentar: reações e métodos diagnósticos. JMPHC. 2013;4(2): 54-63.

11. SOCIEDADE BRASILEIRA DE PEDIATRIA E ASSOCIAÇÃO BRASILEIRA DE ALERGIA E IMUNOPATOLOGIA. Consenso brasileiro sobre alergia alimentar. RMMG 2007;18(1).

12. HOURIHANEJOB, BEDWANI SJ, DEAN TP, WARNER JO. Randomised, double blind, crossover challenge study of allergenicity of peanut oils in subjects allergic to peanuts. Bmj. 1997;314(7087):1084-1088.

13. FOOD STANDARDS AGENCY. Guidance on Allergen Management and Consumer Information. 2016 [acesso em 07 jun 2015]. Disponível em: http://www.food.gov.uk/sites/default/files/multimedia/pdfs/maycontainguide.pdf

14. BERND LAG, SOLÉ D, PASTORINO AC, PRADO EA, CASTRO FFM. Anafilaxia: guia prático para o manejo. Rev. Bras. Alerg. Imunopatol. 2006;29(6): 283-291.

15. MOTTA MEFA, SILVA GAPD, SARINHO ESC. Trato gastrintestinal e alergia alimentar na infância. Rev. Bras. Alerg. Imunopatol. 2002;25(3):81-92.

16. BURKS W, JAMESJ, EIGENMANN P. FOOD ALLERGY. 1 ed. [Online] US: Elsevier Health Sciences; 2011.

17. BIRD JA, BURKS AW. Food allergy and asthma. Primary care respiratory journal. 2009;18(4):258-265.

18. JACKSON KD, HOWIE LD, AKINBAMI LJ. Trends in allergic conditions among children: United States 1997-2011. North County Health Services. 2013;121(1): 1-8.

19. CHADDAD MCC. Informação sobre a presença de alérgenos nos rótulos de alimentos: responsabilidade do estado na garantia dos direitos à saúde e à alimentação adequada da população com alergia alimentar. DEMETRA: Alimentação, Nutrição \& Saúde. 2014;9(1): 369-392.

20. SOLÉ D, AMANCIO OMS, JACOB CM, COCCO RR, SARNI RO. Guia prático de diagnóstico e tratamento da Alergia às Proteínas do Leite de Vaca mediada pela imunoglobulina E. Rev. Bras. Alerg. Imunopatol. 2012;35(6): 203-233.

21. COCCORR, SARNI RO, SILVA L, FILHO NAR, SOLÉ D. Perspectivas futuras no tratamento da alergia alimentar. Rev. Bras. Alerg. Imunopatol. 2007;30(1): 9-12.

22. COCCO RR, CAMELO-NUNES IC, PASTORINO AC, SILVA L, SARNI ROS. Abordagem laboratorial no diagnóstico da alergia alimentar. Rev. Paul. Pediatr. 2007;25(3): 258-265. 
23. SAMPSON HA. Update on food allergy. Journal of Allergy and Clinical Immunology. 2004;113(5): 805-819.

24. SAMPSON HA, MUÑOZ-FURLONG A, BOCK SA, SCHMITT C, BASS R. Symposium on the definition and management of anaphylaxis: summary report. Journal of Allergy and Clinical Immunology. 2005;115(3): 584-591.

25. DE BLOK BMJ, VLIEG-BOERSTRA BJ, OUDE-ELBERINK JNG, DUIVERMAN EJ, DUNNGALVIN AA. Framework for measuring the social impact of food allergy across Europe: a Euro Prevall state of the art paper. Allergy. 2007; 62(7): 733-737.

26. BRASIL. Lei nº. 8.078, de 11 de setembro de 1990. Código de Defesa do Consumidor. Diário Oficial da União. 11 set. 1990.

27. PÕE NO RÓTULO. [acesso em 26 set 2015]. Disponível em:www.poenorotulo.com.br/

28. ROSES JB. Food Allergen Law and the Food Allergen Labeling and Consumer Protection Act of 2004: Falling Short of True Protection for Allergy Sufferers. Food and drug law journal. 2011; 66 (2): 224-242.

29. U.S. FOOD AND DRUG ADMINISTRATION. Food allergen labeling and consumer protection act of 2004 [acesso em 06 out 2015]. Disponível em:http://www.fda.gov/Food/GuidanceRegulation/GuidanceDocumentsRegulatorylnformation/ Allergens/ucm106187.htm

30. UNIÃO EUROPEIA. Diretoria do parlamento europeu e conselho $n^{\circ} .89$, de novembro de 2003. Jornal Oficial da União Europeia 25 jun 2003 [acesso em 20 jun 2015]. Disponivel em: https://www.ivdp.pt/pt/docs/legislacao/209.pdf

31. FOOD STANDARDS CODE - STANDARD 1.2.3. Mandatory warning and advisory statements and declarations 2014. Australia; New Zeland [acesso em 20 jun 2015]. Disponívelem: https://www.legislation.gov.au/Details/F2011C00610

32. FOOD STANDARDS. Food recall statistic 2015 [acesso em 06 out 2015]. Australia; New Zeland. Disponível em: http://www. foodstandards.gov.au/industry/foodrecalls/recallstats/pages/default.aspx

33. SICHERER, S.H. Clinical implications of cross-reactive food allergens. Journal of Allergy and Clinical Immunology. 2001;108(6): 881-890.

34. U.S. FOOD AND DRUG ADMINISTRATION. The Reportable Food Registry: target ing inspection resources and identifying patterns of adulteration 2014 [acesso em 06 out 2015]. Disponível em: http://www.fda.gov/downloads/Food/ ComplianceEnforcement/RFR/UCM395684.pdf 